\title{
Are Poker Players All the Same? Latent Class Analysis
}

\section{Magali Dufour 1 , $^{*}$}

Phone +1-450-4631835 Email Magali.Dufour@usherbrooke.ca

Natacha Brunelle 2

Élise Roy 1

${ }^{1}$ Faculty of Medicine (Addiction Program), Université de Sherbrooke (Campus Longueuil), 150, Place Charles-Le Moyne (Bureau 200), Longueuil, QC, J4K 0A8 Canada

2 Department of Special Education, Université du Québec à Trois-Rivières, C.P. 500, Trois-Rivières, QC, G9A 5H7 Canada

\section{Abstract}

Poker is the gambling game that is currently gaining the most in popularity. However, there is little information on poker players' characteristics and risk factors. Furthermore, the first studies described poker players, often recruited in universities, as an homogeneous group who played in only one of the modes (land based or on the Internet). This study aims to identify, through latent class analyses, poker player subgroups. A convenience sample of 258 adult poker players was recruited across Quebec during special events or through advertising in various media. Participants filled out a series of questionnaires (Canadian Problem Gambling Index, Beck Depression, Beck Anxiety, erroneous belief and alcohol/drug consumption). The latent class analysis suggests that there are three classes of poker players. Class I (recreational poker players) includes those who have the lowest probability of engaging intensively in different game modes. Participants in class II (Internet poker players) all play poker on the Internet. This class includes the highest proportion of players who consider themselves experts or professionals. They make a living in part or in whole from poker. Class III (multiform players) includes participants with the broadest variety of poker patterns. This group is complex: these players are 
positioned halfway between professional and recreational players. Results indicate that poker players are not an homogeneous group identified simply on the basis of the form of poker played. The specific characteristics associated with each subgroup points to vulnerabilities that could potentially be targeted for preventive interventions.

\section{Keywords}

Poker players

Latent class analysis

Gambling patterns

Poker gambling problems

Impulsivity

Erroneous beliefs

\section{Introduction}

At this time, the fastest growing form of gambling is poker, particularly Texas Hold'em (Chevalier and Pastinelli 2008; Griffiths et al. 2010; McCormack and Griffiths 2012; National Center for Responsible Gambling 2006; Liley and Rakow 2010; Shead et al. 2008; Wood and Williams 2009; Wiebe et al. 2006). This complex, multi-faceted game involves mathematics, psychology and luck (Siler 2010). Poker has become omnipresent in our society and is accessible in a variety of places and forms (land-based, on the Internet, with friends or in casinos). In 2009, $4.7 \%$ of adults in Quebec reported having played poker in the past year (Kairouz et al. 2010). The number of players was even higher in Ontario since, according to a telephone survey, $21 \%$ of respondents aged 18 and over had played poker for money (Responsible Gambling Council 2006). The European Council (2012) has also reported that the phenomenon is growing.

This worldwide poker craze, occasionally designated by some researchers as "poker mania" (Mitrovic and Brown 2009; Chevalier and Pastinelli 2008), stems mostly from the rapidly increasing availability of the game, greater access through different forms (cash game or tournament) of the game, and wide media coverage (Griffiths et al. 2006; Wood et al. 2007). The substantial amounts awarded during tournaments as well as celebrity endorsements also contribute to its popularity (Liley and Rakow 2010; Shead et al. 2008). Moreover, the structural composition of this game, 
particularly the skill component, raises player interest (Bjerg 2010; Dufour et al. 2012; Liley and Rakow 2010; Siler 2010). Despite the marked increase in poker-related activities, relatively few studies have examined poker players (Bjerg 2010; Dufour et al. 2012; Hopley et al. 2011; Khazaal et al. 2013; Radburn and Horsley 2011; Shead et al. 2008). In particular, very little is known about the association patterns that may exist between the poker players' gambling habits (type and number of games played), their erroneous thoughts, and their gambling problems. It is possible that the choice of poker activities, and more specifically, the combination of activities and some associated characteristics, are as important as the playing frequency in the prediction of gambling problems. Moreover, we do not know if poker players are a homogeneous group or if there are different subgroups. Finally, a better understanding of these subgroups would allow doing more targeted prevention messages. Our study explored a typology of poker players with respect to playing habits and proficiency; we also examined factors that, based on the literature, could increase the risks of developing gambling problems.

\section{Studies of Poker Players}

Our review of the studies conducted with poker players points out the specific characteristics of this population of gamblers. An initial Canadian study of 513 undergraduate students who gambled regularly (at least twice a week) showed that poker players were more likely to be male, younger, consume more alcohol, spend more time gambling, and gamble more frequently compared to non-poker players (Shead et al. 2008). Moreover, poker players reported more severe gambling problems compared to non-poker players (Shead et al. 2008). Therefore, poker players are different from other types of gamblers (Shead et al. 2008).

Studies focused on describing samples composed of poker players only, particularly online poker players, highlight the important prevalence of gambling problems among players. Laplante et al. (2009) conducted a study of 3,445 players playing poker on BWin. They identified two subgroups of online poker players: the first were moderate gamblers and the second, representing $5 \%$ of this population, were more intensely involved and potentially problem gamblers. A study by Wood et al. (2007) of 422 student online poker players reported that $18 \%$ were considered problem gamblers and a further $30 \%$ at risk of developing gambling problems. Other studies have also observed high prevalence rates of pathological gambling (8-9\%) and problem gambling (15-38 \%) among online poker players (Jonsson 2009; Hopley and Nicki 
2010 ). Problem poker players are characterized by a lack of discipline, significant spending, and higher frequency of gambling (Griffiths et al. 2010). Lastly, gambling problems among poker players are linked to erroneous beliefs, impulsivity, and problems managing and identifying emotions (Hopley and Nicki 2010; Mitrovic and Brown 2009; Shead et al. 2008).

Initial data concerning poker players' gambling habits raise concerns. They indicate that numerous poker players are at risk of developing pathological gambling problems, perhaps especially online players. In fact, some authors even state that online poker players are a new breed of problem gamblers (Griffiths et al. 2010). Unfortunately, several of these studies do not take into account all the activities (tournament or cash game) and the modality (Internet or poker room) of poker, not permitting to evaluate whether certain patterns in gambling habits permit to distinguish people at risk. Similarly, many of these studies only consider one single type of poker player- often online-making it difficult to identify the existence of subgroups among poker players. However, latent class studies conducted among Internet gamblers show that these Internet gamblers are heterogeneous and composed of several subgroups, differing markedly on both demographic and clinical characteristics (Lloyd et al. 2010).

Presently, some authors intuitively group poker players into different subgroups. For instance, Shead et al. (2008) observed differences between online/casino poker players and those who play only with friends (social players). In a qualitative study of nine participants, McCormack and Griffiths (2012) drew attention to differences between professional and recreational poker players. Although these subgroups are interesting, they consider only a single variable, such as the form of the game or proficiency, thus neglecting the complexity of poker players' gambling patterns. In fact, these studies neglected to examine whether there were specific patterns of poker activities and other poker-related characteristics (erroneous thoughts and proficiency) that were associated with problematic gambling. Latent class analysis (LCA), in which poker activity data are dichotomized, is a powerful statistical technique that can be used to determine whether groups of individuals who do or do not engage in specific activities, and who have certain characteristics, exist (Boldero et al. 2010). This technique assumes that if there are distinct latent classes (or groups) of individuals, they can be distinguished from one another using these multiple categorical indicators (Lazarsfeld and Henry 1968). The primary advantage of LCA over alternative approaches, such as cluster analysis, is the reliance on a model-based method for estimating population characteristics derived from sample data, adjustment of estimates for measurement 
error, formal statistical procedures for determining the number of classes, use of probabilities as the basis for interpretation of results, and flexible treatment of variance among classes (Magidson and Vermunt 2002; Nylund et al. 2007). Although, not yet used in poker research, LCA has been reported in recent studies interested in the existence of a specific pattern of gambling activities in different populations (Boldero et al. 2010; Cunningham-Williams and Hong 2007; Goodriaan et al. 2009; Lloyd et al. 2010).

We carried out this study to increase the understanding of poker players and to better target those at risk. Our aim was to explore the presence of subgroups of poker players based on two concepts: (1) regular poker playing patterns (playing more than once a month), taking into account the various forms (Internet, poker room, casino, with friends); and (2) level of proficiency (poker-related income and level of expertise perceived by the player). These variables were chosen with reference to various authors who grouped poker players by gambling form (Shead et al. 2008) and level of proficiency (Bjerg 2010; McCormack and Griffiths 2012). A secondary objective was to determine if subgroups could be differentiated in terms of sociodemographic factors, gambling patterns, severity and issues associated with poker gambling problems.

\section{Method}

The study design involves a survey of a convenience sample of 258 poker players from 16 regions of Québec. They were recruited in various poker playing places (casino, tournaments in bars, tournaments in poker rooms), through ads on poker information Websites and through various ads in regional and cultural newspapers, between the months of October 2007 and October 2009. To participate in the study, individuals had to consider themselves as poker players, have bet money on a poker game in the past year, be at least 18 years old, and speak French or English. After signing consent forms, eligible individuals each completed an interviewer-administered questionnaire lasting approximately $90 \mathrm{~min}$. They were paid a monetary stipend of CAN\$30 for their participation. Ethical approval was provided by the Comité d'éthique de la recherché en santé chez l'humain du CHUS and the University of Sherbrooke.

\section{Instruments}

General sociodemographic information was collected for each participant: sex, age, education, marital status, number of children, employment status, place of birth, first 
language, and economic situation. Gambling habits and severity of gambling problems were assessed using the Canadian Problem Gambling Index (CPGI) (Ferris and Wynne 2001 ). Severity of gambling problems was evaluated using the 9-item Problem

Gambling Severity Index (PGSI), with scores ranging from 0 to 27. The instrument was also used to create four categories of players: (0) no risk; (1-2) low risk; (3-7) moderate risk; and (8-27) problem gamblers. Players' level of expertise was assessed with the following questions: (1) Do you consider yourself to be a beginner, intermediate, expert or professional poker player? (2) Do you play poker to make a living ("yes"; "no, but poker playing is part of my income"; "no")?

Associated problems were measured using the following instruments. (1) The Beck Anxiety Inventory (BAI) (Beck et al. 1988), a 21-item scale that assesses the intensity of affective, cognitive and somatic symptoms of anxiety experience in the past week. This continuous scale discriminates anxious individuals who meet the clinical threshold from non-anxious individuals. The validated French version has excellent methodological qualities (Freeston et al. 1994). (2) The Beck Depression Inventory (BDI), a 21-item test that evaluates the main symptoms of depression in the past week (Beck et al. 1996). The French version has good methodological qualities (Bourque and Beaudette 1982). (3) The DEBA-Alcohol and DEBA-Drugs questionnaires (Dépistage-évaluation du besoin d'aide-alcool ou drogue) (Tremblay et al. 2001), screening and evaluation questionnaires used to assess the severity of alcohol and drug consumption as well as addiction to these substances in the past year. They show good validity and reliability indices (Tremblay et al. 2001). (4) Impulsivity was assessed using a 43-item questionnaire (Eysenck and Eysenck 1977), which was validated through a process of translation into French and back-translation into English (Jacques et al. 1997). (5) Lastly, the Inventaire des croyances liées aux jeux (ICROLJ), an inventory of gambling-related beliefs developed by Ladouceur et al. (2004), was used to evaluate the relative magnitude of erroneous beliefs held by the players. Three types of beliefs were assessed: (a) illusion of control; (b) independence between events; and (c) superstitions. All statements were rated on a 4-point Likert-type scale. The final version of the instrument included 24 statements.

\section{Data Analysis}

Descriptive statistics such as percentages and frequencies were used to describe demographic characteristics and proportions of the sample reporting various gambling activities. Latent class analysis was applied to the poker playing habits (playing once a 
month) of all players, taking into account different forms of poker (Internet, casino, poker room, with friends) and level of proficiency (income associated with poker, player's perception of level of expertise) to identify subgroups with particular gambling behaviours. To establish player profiles, six dichotomous variables were used: (1) plays poker in a poker room at least once a month; (2) plays poker online at least once a month; (3) plays poker with friends at least once a month; (4) plays poker at the casino at least once a month; (5) considers himself or herself to be an expert or professional poker player; (6) earns his or her living as a professional poker player or in part by playing poker. Decisions concerning the most appropriate latent class model for a sample must be guided by statistical indices as well as conceptual considerations (i.e. latent classes must be significant and distinct). The best number of latent classes was determined using the bootstrap likelihood ratio test (BLRT), as suggested by Nylund et al. (2007). This test compares the overall fit between a model with k-1 class and a model with $\mathrm{k}$ class. If the $p$ value is smaller than 0.05 then using a k class model rather than a k-1 class model significantly improves the fit. The model selection was also based on the Adjusted Bayesian Information Criterion (ABIC), where a lower value indicates better fit. The maximum likelihood method was used to estimate models, and different starting values were used to avoid local maxima. The assumption of local independence was verified using bivariate residuals (Vermunt and Magidson 2007 ). Participants were assigned to classes based on the posterior probabilities of class membership given gambling patterns. LCA was performed using MPlus version 6.1 (Muthén and Muthén 2010). Once subgroups of individuals were identified, their sociodemographic characteristics, gambling patterns, gambling-associated problems, and severity of gambling problems were compared using Chi square test for nominal and dichotomous variables. Single-factor ANOVA tests were performed for continuous variables. Finally, multiple comparisons were made using the Bonferroni test.

\section{Results}

Of the 258 poker players who completed interviews, $88.4 \%$ were men and $11.6 \%$ women. Their ages ranged from 18 to 68 years $(\mathrm{M}=29.8$ years, $\mathrm{SD}=10.8$ years). Among these players, $62.4 \%$ were working and $30 \%$ were students. Most of these players were educated since $66.2 \%$ of them had at least a high school diploma, that is, had completed grade 12 . Lastly, $51.6 \%$ of participants were in common-law relationships or married, and $48.4 \%$ were single, divorced or separated.

\section{Class Membership}


Based on the BLRT, the 3-class model was selected over the 2-class (BLRT; $p<0.001$ ) and 4-class (BLRT; $p=0.405$ ) models. Furthermore, the 3-class model had the lowest ABIC $(1,781.393)$ and highest entropy $(0.681)$, and met the local independence assumption since none of its bivariate residuals were significant. Table 1 presents the 3-class solution as well as each class membership probability.

\section{Table 1}

Conditional probabilities for each poker gambling behaviors as a function of latent class membership

\begin{tabular}{|c|c|c|c|c|}
\hline & \multicolumn{3}{|l|}{ Classes } & \multirow[b]{2}{*}{ Overall } \\
\hline & $\begin{array}{l}\text { Class I: } \\
\text { Recreational } \\
\text { players } \\
(\mathbf{R P}) \\
(\mathbf{N}=\mathbf{1 6 0})\end{array}$ & $\begin{array}{l}\text { Class II: } \\
\text { Internet } \\
\text { players } \\
(\mathrm{IP}) \\
(\mathrm{N}=43)\end{array}$ & $\begin{array}{l}\text { Class III: Multiform } \\
\text { players (MP) }(\mathrm{N}=\mathbf{5 5})\end{array}$ & \\
\hline $\begin{array}{l}\text { Probability of } \\
\text { belonging }\end{array}$ & 0.601 & 0.205 & 0.194 & 1 \\
\hline \multicolumn{5}{|c|}{ Conditional probabilities } \\
\hline $\begin{array}{l}\text { Plays in poker } \\
\text { rooms }^{\mathrm{b}}\end{array}$ & 0.351 & 0.548 & 0.849 & 0.494 \\
\hline $\begin{array}{l}\text { Plays poker } \\
\text { on the } \\
\text { Internet }^{\text {b }}\end{array}$ & 0.500 & 1.000 & 0.591 & 0.620 \\
\hline $\begin{array}{l}\text { Plays poker } \\
\text { with friends }\end{array}$ & 0.577 & 0.423 & 1.000 & 0.628 \\
\hline $\begin{array}{l}\text { Plays poker in } \\
\text { casinos }^{b}\end{array}$ & 0.002 & 0.348 & 0.344 & 0.140 \\
\hline $\begin{array}{l}\text { Expert or } \\
\text { professional }\end{array}$ & 0.076 & 0.727 & 0.473 & 0.287 \\
\hline $\begin{array}{l}\text { Poker is part } \\
\text { of income }\end{array}$ & 0.043 & 0.676 & 0.591 & 0.279 \\
\hline \multicolumn{5}{|c|}{$\begin{array}{l}\text { aprobabilities of belonging to each latent class denotes the probability of being in latent } \\
\text { class } t=1,2 \text { or } 3 \text { (il s'agit d'une estimation de la prévalenee des classes caleulée par le } \\
\text { modèle) }\end{array}$} \\
\hline \multicolumn{5}{|c|}{$\begin{array}{l}\text { Conditional probabilities in bold refer to one-third larger than overall, and in italic one- } \\
\text { third smaller than overall }\end{array}$} \\
\hline
\end{tabular}


When compared with the other two classes, the first class - representing $62.0 \%$ of the sample $(\mathrm{n}=160)$ - included individuals with the least probability of getting intensely involved in various gambling forms (online, poker room in bar or casino), lowest level of proficiency, and lowest probability of earning a living in part or in whole by playing poker. These players are termed "recreational players" (RP). Participants in the second class $(16.7 \%$ of the sample; $n=43)$ have a $100 \%$ probability of playing poker on the Internet, even though they also play in poker rooms, with friends and in casinos. They are more likely to see themselves as experts and to make a living, in whole or in part, by playing poker. We call these players "Internet players" (IP). Participants in the third class $(21.3 \%$ of the sample; $\mathrm{n}=55)$ have the highest probability of playing in poker rooms and with friends, while playing on the Internet and in casinos less frequently. They have a high probability of perceiving themselves to be experts (a bit less than persons in class II) and of earning their living in part or in whole by playing poker (quite close to class II). These are "multiform players" (MP).

Table 2 shows the number and percentage of respondents in each class as well as their demographic characteristics. No sociodemographic differences between classes were observed for age, employment status, level of education, marital status or income.

\section{Table 2}

Sociodemographic characteristics across classes of players

\begin{tabular}{|c|c|c|c|c|}
\hline \multirow{2}{*}{ Variable } & \multicolumn{3}{|l|}{ Classes } & \multirow[b]{2}{*}{$p$ value } \\
\hline & $\begin{array}{l}\text { RP } \\
(N=160)\end{array}$ & $\begin{array}{l}\text { IP } \\
(\mathrm{N}=43)\end{array}$ & $\begin{array}{l}\text { MP } \\
(\mathrm{N}=55)\end{array}$ & \\
\hline Sex men & $85.0 \%$ & $97.7 \%$ & $90.1 \%$ & 0.057 \\
\hline Mean age & 29.9 & 31.4 & 28.6 & 0.452 \\
\hline \multicolumn{5}{|c|}{ Employment status } \\
\hline$\%$ Worker & $86.3 \%$ & $81.4 \%$ & $85.5 \%$ & 0.963 \\
\hline$\%$ Student & $10.6 \%$ & $11.6 \%$ & $10.9 \%$ & \\
\hline$\%$ Other & $3.1 \%$ & $7.0 \%$ & $3.6 \%$ & \\
\hline
\end{tabular}


Education level

\begin{tabular}{|l|l|l|l|l|}
\hline$\%$ High school diploma & $30.6 \%$ & $35.7 \%$ & $41.8 \%$ & 0.305 \\
\hline$\%$ College or university degree & $69.4 \%$ & $64.3 \%$ & $58.2 \%$ & \\
\hline Average income & $\$ 33,011$ & $\$ 31,036$ & $\$ 37,745$ & 0.406 \\
\hline Marital status & & & & \\
\hline$\%$ Common-law or married & $52.2 \%$ & $55.8 \%$ & $45.5 \%$ & 0.552 \\
\hline \% Single, widowed or divorced & $47.5 \%$ & $44.2 \%$ & $54.5 \%$ & \\
\hline
\end{tabular}

\section{Characteristics Associated with Each Latent Class}

\section{Gambling}

Number of gambling games played in the past year, money spent by type of game, and severity of gambling habits were compared among the three classes (Table 3 ). In the past year, RP played fewer gambling games than IP and $\mathrm{MP}(\mathrm{F}(2,255)=11.59$, $p<0.001)$. Moreover, RP spent significantly less money than IP on video lottery terminals in bars, gambling on the Internet (other than poker), and all forms of poker (tournaments vs. cash games) and poker places (poker room, Internet, casino, with friends) (Tables 3 and 4). RP spent significantly less money than MP playing poker with friends and cash games in poker rooms. For their part, IP differ from MP since they spent significantly more money playing poker in casinos and online, and tended to spend more when they played cash games and other gambling games on the Internet.

\section{Table 3}

Gambling patterns across classes of players

\begin{tabular}{|l|l|l|l|l|}
\hline \multicolumn{3}{|c|}{ Classes } & \\
\cline { 2 - 5 } & $\begin{array}{l}\text { RP } \\
\mathbf{( N = 1 6 0 )}\end{array}$ & $\begin{array}{l}\text { IP } \\
\mathbf{( N = 4 3 )}\end{array}$ & $\begin{array}{l}\text { MP } \\
\mathbf{( N = 5 5 )}\end{array}$ & p value \\
\hline $\begin{array}{l}\text { Average number of games played } \\
\text { in the past year }\end{array}$ & 7.0 & 8.5 & 9.0 & $<0.001^{* * *}$ \\
\hline Average amount of money spent on each occasion, in $\$$ & & \\
\hline Lottery tickets & $\begin{array}{l}\$ 3.6 \\
(\mathrm{~N}=121)\end{array}$ & $\begin{array}{l}\$ 4.79 \\
(\mathrm{~N}=24)\end{array}$ & $\begin{array}{l}\$ 8.8 \\
(\mathrm{~N}=35)\end{array}$ & 0.592 \\
\hline
\end{tabular}




\begin{tabular}{|c|c|c|c|c|}
\hline Horse races & $\begin{array}{l}\$ 27.0 \\
(\mathrm{~N}=6)\end{array}$ & $\begin{array}{l}\$ 139.0 \\
(\mathrm{~N}=5)\end{array}$ & $\begin{array}{l}\$ 49.0 \\
(\mathrm{~N}=6)\end{array}$ & 0.279 \\
\hline Slot machines in casinos & $\begin{array}{l}\$ 45.7 \\
(\mathrm{~N}=57)\end{array}$ & $\begin{array}{l}\$ 50.1 \\
(\mathrm{~N}=12)\end{array}$ & $\begin{array}{l}\$ 56.7 \\
(\mathrm{~N}=26)\end{array}$ & 0.829 \\
\hline Video lottery terminals in bars & $\begin{array}{l}\$ 19.0 \\
(\mathrm{~N}=59)\end{array}$ & $\begin{array}{l}\$ 52.7 \\
(\mathrm{~N}=12)\end{array}$ & $\begin{array}{l}\$ 39.8 \\
(\mathrm{~N}=21)\end{array}$ & $0.018^{*}$ \\
\hline $\begin{array}{l}\text { Gambling on the Internet (other } \\
\text { than poker) }\end{array}$ & $\begin{array}{l}\$ 20.8 \\
(\mathrm{~N}=12)\end{array}$ & $\begin{array}{l}\$ 141.3 \\
(\mathrm{~N}=8)\end{array}$ & $\begin{array}{l}\$ 30.3 \\
(\mathrm{~N}=8)\end{array}$ & $0.001 * * *$ \\
\hline Poker in a casino & $\begin{array}{l}\$ 163.0 \\
(N=42)\end{array}$ & $\begin{array}{l}\$ 492.0 \\
(\mathrm{~N}=30)\end{array}$ & $\begin{array}{l}\$ 200.6 \\
(N=38)\end{array}$ & $<0.001 * * *$ \\
\hline Poker in a poker room & $\begin{array}{l}\$ 34.7 \\
(\mathrm{~N}=105)\end{array}$ & $\begin{array}{l}\$ 97.6 \\
(\mathrm{~N}=36)\end{array}$ & $\begin{array}{l}\$ 60.2 \\
(\mathrm{~N}=52)\end{array}$ & $0.004 * *$ \\
\hline Poker with friends & $\begin{array}{l}\$ 17.5 \\
(\mathrm{~N}=139)\end{array}$ & $\begin{array}{l}\$ 50.9 \\
(\mathrm{~N}=31)\end{array}$ & $\begin{array}{l}\$ 40.3 \\
(\mathrm{~N}=55)\end{array}$ & $0.008 * *$ \\
\hline Poker on the Internet & $\begin{array}{l}\$ 13.4 \\
(\mathrm{~N}=86)\end{array}$ & $\begin{array}{l}\$ 114.5 \\
(\mathrm{~N}=42)\end{array}$ & $\begin{array}{l}\$ 26.1 \\
(\mathrm{~N}=38)\end{array}$ & $<0.001 * * *$ \\
\hline Cash game on the Internet & $\begin{array}{l}\$ 43.5 \\
(\mathrm{~N}=76)\end{array}$ & $\begin{array}{l}\$ 642.3 \\
(\mathrm{~N}=35)\end{array}$ & $\begin{array}{l}\$ 201.5 \\
(\mathrm{~N}=32)\end{array}$ & $0.013^{*}$ \\
\hline Cash game in a poker room & $\begin{array}{l}\$ 64.3 \\
(\mathrm{~N}=39)\end{array}$ & $\begin{array}{l}\$ 229.0 \\
(\mathrm{~N}=20)\end{array}$ & $\begin{array}{l}\$ 123.5 \\
(\mathrm{~N}=38)\end{array}$ & $<0.001 * * *$ \\
\hline $\begin{array}{l}\text { Cash game in a poker room or on } \\
\text { the Internet }\end{array}$ & $\begin{array}{l}\$ 64.2 \\
(\mathrm{~N}=93)\end{array}$ & $\begin{array}{l}\$ 726.2 \\
(\mathrm{~N}=37)\end{array}$ & $\begin{array}{l}\$ 273.7 \\
(\mathrm{~N}=46)\end{array}$ & $0.001 * * *$ \\
\hline PGSI Score (continuous) & 1.91 & 4.19 & $3.39^{\mathrm{a}}$ & $<0.001 * * *$ \\
\hline$\%$ No risk or low risk & $69.4 \%$ & $48.8 \%$ & $42.6 \%$ & $0.001 * * *$ \\
\hline$\%$ Moderate or high risk & $30.6 \%$ & $51.2 \%$ & $57.4 \%$ & \\
\hline \multicolumn{5}{|l|}{$* p \leq 0.05 ; * * p \leq 0.01 ; * * * p \leq 0.001$} \\
\hline missing value & & & & \\
\hline
\end{tabular}

\section{Table 4}

Results of Bonferroni tests for significant gambling habit variables

$p$ value

\begin{tabular}{l|l|l} 
RP versus & RP versus & IP versus \\
MP & IP & MP
\end{tabular}




\begin{tabular}{|l|l|l|l|}
\hline $\begin{array}{l}\text { Average number of games played in the } \\
\text { past year }\end{array}$ & $<0.001^{* * *}$ & $0.01^{* *}$ & 1 \\
\hline $\begin{array}{l}\text { Average amount of money spent on each } \\
\text { occasion }\end{array}$ & 0.168 & $0.041^{*}$ & 1 \\
\hline VLT in bars & 1 & $0.027^{*}$ & 0.075 \\
\hline Gambling on the Internet & 1 & $0.001^{* * *}$ & $0.007^{* *}$ \\
\hline Poker in casinos & 0.323 & $0.004^{* *}$ & 0.297 \\
\hline Poker in poker rooms & $0.05^{*}$ & $0.039^{*}$ & 1 \\
\hline Poker with friends & 1 & $<0.001^{* * *}$ & $0.001 * * *$ \\
\hline Poker on the Internet & 1 & $0.01^{* *}$ & 0.251 \\
\hline $\begin{array}{l}\text { Cash games (poker) on the Internet } \\
\text { Cash games (poker) in poker rooms }\end{array}$ & $0.03 *$ & $<0.001^{* * *}$ & 0.083 \\
\hline $\begin{array}{l}\text { Cash games (poker) online or on the } \\
\text { Internet }\end{array}$ & 0.61 & $0.001^{* * *}$ & 0.077 \\
\hline PGSI Score (continuous) & $0.001^{* * *}$ & $<0.001^{* * *}$ & 0.392 \\
\hline$* p \leq 0.05 ; * * \leq 0.01 ; * * p \leq 0.001$ & & & \\
\hline
\end{tabular}

As for the severity of gambling habits measured with the PGSI, the level of risk is significantly lower for RP than for the other two subgroups of players.

\section{Impulsivity and Erroneous Beliefs}

All groups presented similar rates of impulsivity (Table 5). Similarly, IP, MP and RP showed a comparable level of superstition and had similar erroneous beliefs concerning independence between hands. However, RP showed significantly less illusion of control than IP $(p=0.006)$ and tended to show less than MP $(p=0.058)$ while RP and MP showed similar levels (0.873). Compared with RP, a significantly higher proportion of IP and MP believed that outcome of poker games is a question of skill (at $75 \%$ or + ). Compared with MP, IP also tended to believe that skill determines outcome of poker games $(p=0.066)$.

\section{Table 5}

Impulsivity and erroneous beliefs across classes of players 


\section{Classes}

\begin{tabular}{|c|c|c|c|c|}
\hline \multirow[t]{2}{*}{ Variable } & $\begin{array}{l}\text { RP } \\
(N=160)\end{array}$ & $\begin{array}{l}\text { IP } \\
(N=43)\end{array}$ & $\begin{array}{l}\text { MP } \\
(\mathrm{N}=55)\end{array}$ & \multirow[t]{2}{*}{$p$ value } \\
\hline & Average & Average & Average & \\
\hline Impulsivity & 21.01 & 19.49 & 22.23 & 0.159 \\
\hline \multicolumn{5}{|l|}{ Erroneous beliefs } \\
\hline Superstition ${ }^{\mathrm{b}}$ & 15.50 & 16.68 & 15.21 & 0.192 \\
\hline Illusion of control ${ }^{b}$ & 31.01 & 33.54 & 32.70 & $0.002 * *$ \\
\hline Independence between hands ${ }^{b}$ & 17.64 & 18.27 & 18.30 & 0.299 \\
\hline $\begin{array}{l}\% \text { Poker game outcomes are } 75 \% \text { or }+ \\
\text { attributable to skill (vs. dichotomous) }\end{array}$ & $41.3 \%$ & $79.1 \%$ & $61.8 \%$ & $<0.001 * * *$ \\
\hline \multicolumn{5}{|l|}{$* * p \leq 0.01 ; * * * p \leq 0.001$} \\
\hline \multicolumn{5}{|l|}{${ }^{\mathrm{a}} 6$ missing value } \\
\hline 7 missing values & & & & \\
\hline
\end{tabular}

\section{Associated Mental Health Problems}

All three groups presented low levels of anxiety (Table 6). MP had significantly higher depression scores than IP $(p=0.007)$. However, these scores were borderline "normal" or "mild depression". Regarding alcohol and drug use problems, the three subgroups showed no significant differences. However, significantly fewer IP drank alcohol while playing poker when compared to RP $(p=0.001)$ and MP $(p=0.008)$. Similarly, a significantly lower proportion of IP reported using drugs while playing poker than did the other two classes of players [RP $(p=0.026)$ and MP $(p=0.002)]$.

\section{Table 6}

Mental health problems across classes of players

\begin{tabular}{|c|c|c|c|c|}
\hline \multirow{3}{*}{ Variable } & \multicolumn{3}{|l|}{ Classes } & \multirow{3}{*}{$p$ value } \\
\hline & $\begin{array}{l}R P \\
(N=160)\end{array}$ & $\begin{array}{l}\text { IP } \\
(\mathrm{N}=43)\end{array}$ & $\begin{array}{l}\text { MP } \\
(N=55)\end{array}$ & \\
\hline & Average & Average & Average & \\
\hline
\end{tabular}




\begin{tabular}{|c|c|c|c|c|}
\hline Anxiety ${ }^{a}$ & 6.07 & 4.20 & 6.57 & 0.128 \\
\hline Depression $^{\mathrm{b}}$ & 5.07 & 3.30 & 6.75 & $0.009 * *$ \\
\hline Alcohol problems ${ }^{\mathrm{a}}$ & 2.44 & 2.09 & 2.71 & 0.712 \\
\hline Drug problems ${ }^{\mathrm{a}}$ & 0.64 & 0.35 & 1.13 & 0.078 \\
\hline $\begin{array}{l}\% \text { Who drank alcohol while playing } \\
\text { poker }\end{array}$ & $78 \%$ & $46.5 \%$ & $72.7 \%$ & $<0.001 * * *$ \\
\hline$\%$ Who used drugs while playing poker & $28.1 \%$ & $11.6 \%$ & $40 \%$ & $0.008 * *$ \\
\hline \multicolumn{5}{|l|}{$* * p \leq 0.01 ; * * * p \leq 0.001$} \\
\hline \multicolumn{5}{|l|}{${ }^{\mathrm{a}} 6$ missing value } \\
\hline b7 missing values & & & & \\
\hline
\end{tabular}

\section{Discussion}

The goal of this study was to examine the potential existence of distinct subgroups of poker players. We considered two concepts of regular poker-playing patterns, taking into account various forms of playing (Internet, casino, poker room, and with friends), and perceived level of proficiency (income from poker and level of expertise). A LCA allowed us to empirically identify three subgroups of poker players. Therefore, poker players are not a homogeneous group identified simply on the basis of the form of poker played. These results partly substantiate intuitive groups established by various authors, who used level of expertise reported (Bjerg 2010; McCormack and Griffiths 2012 ) or form of poker game (Shead et al. 2008) to distinguish poker players. However, our LCA allowed us to go beyond these initial observations since it underlined the complex links between gambling habits and level of expertise reported by players. Despite certain similarities among them, several significant differences that emerged among the groups of poker players enabled us to note the specific characteristics of each group.

In our study, the first class of players, which included a majority of participants (62\%), were recreational players (RP). Although most of these players played several forms of poker (Internet, poker room, and with friends), their gambling habits set them apart from the other two subgroups (IP and MP). RP reported spending significantly less money on most forms of gambling games and poker than IP; they also spend less 
money than MP on many forms of games and poker, with the exception of horse racing and slot machines in casinos. These players also showed less illusion of control and consumed the most alcohol while playing poker. These RP resemble the recreational players described in McCormack and Griffiths' (2012) qualitative study, where players sometimes gambled under the influence of substances, took more risks and occasionally engaged in chasing behaviour (McCormack and Griffiths 2012). Loss of control observed in some recreational players probably reflects emerging gambling problems, although the RP subgroup includes a lower proportion of players at risk or who have gambling problems (30.6\%) than the other two subgroups. This result is similar to those found by other studies among poker players. A research conducted among student online poker players reported that $30 \%$ of them were at risk of developing gambling problems (Wood et al. 2007; Griffiths et al. 2010). These results indicate that less intense regular poker playing patterns can nonetheless contribute to the emergence of negative consequences.

The second class was composed of Internet players (IP) and represented $16.7 \%$ of players in our study. These players, all of whom played on the Internet, also engaged in other forms of poker, but in a smaller proportion. In fact, these players were the ones who played poker with friends the least regularly. It was also in this subgroup that we found the highest proportion of players who considered themselves experts or professionals, and who made a living from poker, in part or in whole. These IP are similar to both the professional players observed in other studies (Bjerg 2010; McCormack and Griffiths 2012) and to those grouped under the term "Casino/Internet players" (Shead et al. 2008). These players also reported the lowest level of depression, even if none of the three groups reached the clinical threshold for mental health problems. The players in this group had more intense gambling and poker patterns and spent more money on all gambling games than did the RP. Similarly, IP spent significantly more money than MP on poker in casinos and online poker, and tended to spend more on cash games. Other studies (Shead et al. 2008) have also observed higher spending among Internet poker players. These players were the ones who used substances the least while playing poker. IP were also those who perceived the most that the outcome of poker games is largely attributable to their skills. Yet, even though the issue of skill in poker playing is complex and must be understood differently than for other gambling games (Bjerg 2010), having a high illusion of control is a characteristic that separates problem poker players from those who do not have gambling problems (Mitrovic and Brown 2009). Since prior studies have 
observed positive links between irrational cognitions and the development of gambling problems (Joukhador et al. 2004; Wohl et al. 2007), the high illusion of control seen in this subgroup could be a significant risk factor for this group. Moreover, the proportion of players at risk and problem gamblers in this subgroup is similar to that observed in other studies of Internet gamblers (Griffiths et al. 2010; Hopley and Nicki 2010; Shead et al. 2008). Although this study observed a high prevalence of problem gambling, the absence of depression or anxiety problems raises the question whether these players have clinical problems or that the assessment instrument used, the EPGFPGSI, is too sensitive for poker players? In fact, some authors have questioned the sensitivity of assessment instruments, especially among professional poker players, for whom it might be difficult to reveal their gambling habits to their close ones, given the moralistic view towards gambling in our society (Bjerg 2010; Dufour et al. 2012; Hopley and Nicki 2010). In summary, like professional players observed in other studies (Bjerg 2010; McCormack and Griffiths 2012), IP treated poker playing as serious, well-paying work where loss of control is not an acceptable option. However, the substantial proportion of players presenting negative consequences highlights the need for prevention targeting these players, especially in terms of the control one can have over a game where the role of luck cannot be quantified.

The third class of players, multiform players (MP), shared characteristics with both IP and RP. Of the three poker player groups, MP were the ones who had the broadest variety of poker patterns. While all MP played with friends, they also made up the largest proportion of those who played in poker rooms. In addition, many of them played on the Internet. MP spent similar amounts as RP on different forms of poker. However, MP had higher levels of illusion of control than did RP, levels that were similar to the IP group. Such a strong belief in control, often associated with professional players, is at variance with substance consumption while playing poker, a risk associated with recreational players and with players who lose control (McCormack and Griffiths 2012). In fact, just like RP, this group consumed more substances while playing than IP, which indicates that they engaged in this activity as a form of recreation and in contexts where there is alcohol on the premises. Moreover, the proportion of people at risk $(57.4 \%)$ was similar to that observed among IP, but significantly higher than among RP. Actually, the proportion of individuals considered at risk was similar to that observed in other studies among "Casino/Internet" players (Shead et al. 2008). Yet, although these players also played on the Internet, several of their characteristics were different enough to form a group with its own identity. 
Finally, this group scored higher on the depression scale than the IP group, although these results are below the clinical threshold for mental health problems. The characteristics associated with this group highlight its complexity, which seems to be positioned halfway between professional and recreational players. While other studies created groups similar to the first two classes (Internet players and recreational players), they seem to have ignored multiform players (MP). However, due to the strong beliefs regarding control as well as drug and alcohol use while playing poker, this group presents its own risk factors, suggesting the need for specific interventions.

Nonetheless, these interesting results should be considered within the limitations of this study. Although the study sample is composed of poker players in the general population who were recruited in a variety of settings using different strategies, it is still a convenience sample. Players who participated are only those who responded to calls for participants, and we do not know the rate of response. Therefore, we may not have had access to all types of poker players, which limits the generalization of the results, especially those concerning women. Although women were poorly represented in the sample, it is usually the case in other studies among poker players where they represent between 5 and $14 \%$ of the sample (Griffiths et al. 2010; Hopley et al. 2011; Jonsson 2009; LaPlante et al. 2009). In addition, using an instrument to measure erroneous beliefs among poker players that has not yet been validated is not optimal and should be taken into account when interpreting the results. Finally, as Bjerg (2010) and Hopley and Nicki (2010) indicated, using a diagnostic tool that has not been validated for use with poker players, such as the PGSI, must be taken into account, especially when it comes to establishing level of gambling severity.

To sum up, this study has shed light on different groups of poker players that exist in the population. Poker players thus form a heterogeneous group for whom it is not enough to consider form of game only to identify homogeneous subgroups. In fact, the specific characteristics associated with each subgroup (erroneous beliefs, alcohol consumption) point to vulnerabilities that could potentially be targeted for preventive interventions. IP and MP should be the subjects of a targeted campaign discussing notably the risks that may be present when a player invests large amounts of time and money in poker, even in a work perspective. Moreover, these results underline the importance for regulators to integrate responsible gambling measures on Internet sites, particularly in those offering cash game. The integration of these measures on the Internet sites could help the IP group that plays online considerably. Finally, although this study allows us to deepen our understanding of poker players, new longitudinal 
studies examining the evolution of these groups, especially the multiform group, are needed. In addition, studies looking at women in these groups would help qualify the results obtained.

\section{Acknowledgments}

The authors wish to thank Jill Vandermeerschen, Sabrina Champoux and Patricia Auger for their contribution to the preparation of the manuscript. The authors would also like to thank the participants of the study and all members of the research team. This research was supported by Fonds québécois de la recherche sur la société et la culture (FQRSC).

\section{Conflict of interest}

The authors declare that they have no conflict of interest.

\section{References}

Beck, A. T., Epstein, N., Brown, G., \& Steer, R. A. (1988). An inventory for measuring clinical anxiety: Psychometric properties. Journal of Consulting and Clinical Psychology,. doi:10.1037/0022-006X.56.6.893.

Beck, A. T., Steer, R. A., \& Brown, G. K. (1996). Beck Depression Inventory (2nd ed.). San Antonio, TX: The Psychological Corporation.

Bjerg, O. (2010). Problem gambling in poker: Money, rationality and control in a skill-based social game. International Gambling Studies,.

doi:10.1080/14459795.2010.520330.

Boldero, J. M., Bell, R. C., \& Et Moore, S. M. (2010). Do gambling activity patterns predict gambling problem? A latent class analysis of gambling forms among Australian youth. International Gambling Studies, 10(2), 151-163.

Bourque, P., \& Beaudette, D. (1982). Étude psychométrique du questionnaire de dépression de Beck auprès d'un échantillon d'étudiants universitaires francophones. Canadian Journal of Behavioural Science/Revue Canadienne des Sciences du Comportement,. doi:10.1037/h0081254. 
Chevalier, S., \& Pastinelli, M. (2008). L'offre de jeu de poker sous toutes ses coutures ou la sociologie du poker. (Rapport de recherche). Québec, Canada: 76e congrès de l'ACFAS.

Cunningham-Williams, R. M., \& Hong, S. I. (2007). A latent class analysis (LCA) of problem gambling among a sample of community-recruited gamblers. The Journal of Nervous and Mental Disease, 195(11), 939-947.

Điekerson, M. G. (1993). Internal and external determinants of persistent gambling: Problems in generalising from one form of gambling to another. Journat of Gambling Studies,. doi:10.1007/BF01015920.

Dufour, M., Petit, S., \& Brunelle, N. (2012). La perception du poker selon les joueurs adeptes: Un jeu qui les distingue. Revue Criminologie, 45(2), 7-26.

eCommeree and Online Gambling Regulation and Assuranee. (2007). An exploratory investigation into the attitudes and behaviours of Internet easino and poker players. (eCOGRA global online gambling report). UK: Nottingham Trent University.

European Council. (2012). Towards a comprehensive European framework for online gambling (Communication from the commission to the European parliament, the council, the economic and social committee and the committee of the regions). Strasbourg: European Commission.

Eysenck, S. B., \& Eysenck, H. J. (1977). The place of impulsiveness in a dimensional system of personality description. British Journal of Social \& Clinical Psychology, . doi:10.1111/j.2044-8260.1977.tb01003.x.

Ferris, J., \& Wynne, H. (2001). L'indice canadien de jeu excessif. (Rapport de recherche). Ontario: Centre canadien de lutte contre l'alcoolisme et les toxicomanies.

Freeston, M. H., Ladouceur, R., Thibodeau, N., Gagnon, F., \& Rhéaume, J. (1994). L'inventaire d'anxiété de Beck: Propriétés psychométriques d'une traduction française. L'Encéphale, 20, 47-55. 
Goodriaan, A. E., Slutske, W. S., Krull, J. L., \& Sjer, K. J. (2009). Longitudinal patterns of gambling activities and associated risk factors in college students. Addiction, 104, 1219-1232.

Griffiths, M., Parke, A., Wood, R., \& Parke, J. (2006). Internet gambling: An overview of psychosocial impacts. UNLV Gaming Research \& Review Journal, 10(1), 27-39.

Griffiths, M., Parke, J., Wood, R., \& Rigbye, J. (2010). Online poker gambling in university students: Further findings from an online survey. International Journal of Mental Health and Addiction,. doi:10.1007/s11469-009-9203-7.

Hopley, A. A. B., Dempsey, K., \& Nicki, R. (2011). Texas Hold'em online poker: A further examination. International Journal of Mental Health and Addiction,. doi:10.1007/s11469-011-9353-2.

Hopley, A. A. B., \& Nicki, R. M. (2010). Predictive factors of excessive online poker playing. Cyberpsychology, Behavior, and Social Networking,. doi:10.1089/cyber.2009.0223.

Jacques, C., Ferland, F., Giroux, I., Bouchard, C. (1997). Traduction et validation du Questionnaire d'Eysenck. Dans, Ladouceur, R. Boutin, C., Doucet, C., Lachance, S. et Sylvain, C. (2000). Programme d'évaluation et de traitement des joueurs excessifs. Centre pour la prevention et le traitement du jeu, Université Laval.

Jonsson, J. (2009). Responsible gaming and gambling problems among 3000 Swedish Internet poker players (Présentation au congrès de l'Alberta Gaming Research Institute). Alberta, Canada: Banff conference on Internet Gambling.

Joukhador, J., Blaszczynski, A., \& Maccallum, F. (2004). Superstitious beliefs in gambling among problem and non-problem gamblers: Preliminary data. Journal of Gambling Studies,. doi:10.1023/B:JOGS.0000022308.27774.2b.

Kairouz, S., Nadeau, L., \& Paradis, C. (2010). Portrait du jeu au Québec:

Prévalence, incidence et trajectoires sur quatre ans (Rapport de recherche de l'Enquête ENHJEU). Québec, Canada: Université de Concordia. 
Ladouceur, R., Jacques, C., Giroux, I., \& Sévigny, S. (2004). Inventaire des croyances liées au jeu (ICROL-J). Québec: Centre québécois d'excellence pour la prévention et le traitement du jeu, École de psychologie, Université Laval.

LaPlante, D. A., Kleschinsky, J. H., LaBrie, R. A., Nelson, S. E., \& Shaffer, H. J. (2009). Sitting at the virtual poker table: A prospective epidemiological study of actual Internet poker gambling behavior. Computers in Human Behavior, doi:10.1016/j.chb.2008.12.027.

Liley, J., \& Rakow, T. (2010). Probability estimation in poker: A qualified success for unaided judgment. Journal of Behavioral Decision Making, . doi:10.1002/bdm.670.

Lloyd, J., Doll, H., Hawton, K., Dutton, W. H., Geddes, J. R., Goodwin, G. M., et al. (2010). Internet gamblers: A latent class analysis of their behaviours and health experiences. Journal of Gambling Studies, . doi:10.1007/s10899-010-9188-y.

McCormack, A., \& Griffiths, M. D. (2012). What differentiates professional poker players from recreational poker players? A qualitative interview study. International Journal of Mental Health and Addiction,. doi:10.1007/s11469-011-9312-y.

Mitrovic, D. V., \& Brown, J. (2009). Poker mania and problem gambling: A study of distorted cognitions, motivation and alexithymia. Journal of Gambling Studies,. doi:10.1007/s10899-009-9140-1.

Muthén, L. K., \& Muthén, B. O. (2010). Mplus User's guide (6th ed.). Los Angeles, CA: Muthén \& Muthén.

National Center for Responsible Gambling. (2006). 2006 Annual Report (Research report). Washington, DC: Author.

Nylund, K. L., Asparouhov, T., \& Muthén, B. O. (2007). Deciding on the number of classes in latent class analysis and growth mixture modeling: A Monte Carlo simulation study. Structural Equation Modeling, . doi:10.1080/10705510701575396.

Radburn, B., \& Horsley, R. (2011). Gamblers, grinders, and mavericks: The use of membership categorisation to manage identity by professional poker players. 
Journal of Gambling Issues,. doi:10.4309/jgi.2011.26.4.

Responsible Gambling Council. (2006). One-in-five Ontarians play poker for money (Research report). Ontario: Author.

Sévigny, S., Cloutier, M., Pelletier, M., \& Ladoureetr, R. (2005). Internet gambling: Misleading payout rates during the 'demo' period. Computers in Human Beharior', doi:10.1016/j.ehb.2004.02.017.

Shead, N. W., Hodgins, D. C., \& Scharf, D. (2008). Differences between poker players and non-poker-playing gamblers. International Gambling Studies,. doi:10.1080/14459790802139991.

Siler, K. (2010). Social and psychological challenges of poker. Journal of Gambling Studies, . doi:10.1007/s10899-009-9168-2.

Tremblay, J., Rouillard, P., April, N., \& Sirois, M. (2001). Dépistage/Évaluation du besoin d'aide — alcool (DÉBA-alcool) v1. 6p. Québec, Canada: CRT-ALTO et Régie Régionale de la Santé et des Services Sociaux du Québec.

Vermunt, J. K., \& Magidson, J. (2007). Latent class analysis with sampling weights: A maximum likelihood approach. Sociological Methods and Research, 36(1), 87111.

Weiss, S., \& Loubier, S. (2010). Gambling habits of athletes and nonathletes elassified as disordered gamblers. Journat of $P$ syehology. Interdisciplinary and Applied. doi:10.1080/00223980.2010.503248.

Welte, J. W., Bames, G. M., Tidwell, M. O., \& Hoffman, J. H. (2009). The assoeiation of form of gambling with problem gambling among Ameriean youth. Psychology of Addietive Behaviors, . doi:10.1037/a0013536.

Welte, J. W., Barnes, G. M., Tidwell, M. O., \& Hoffman, J. H. (2011). Gambling and problem gambling aeross the lifespan. Jounat of Gambling Studies,. toi:10.1007/s10899-010-9195-z.

Welte, J. W., Barnes, G. M., Wieezorek, W. F., Tidwell, M. O., \& Hoffman, J. H. 
(2007). Type of gambling and availability as risk faetors for problem gambling: A Fobit regression analysis by age and gender. International Gambling Studies,. doi:10.1080/14459790701387543.

Wiebe, J., Mun, P., \& Kauffman, P. (2006). Gambling and problem gambling in Ontario 2005 (Research report). Ontario: Responsible Gambling Council.

Wohl, M. J. A., Young, M. M., \& Hart, K. E. (2007). Self-perceptions of dispositional luck: Relationship to DSM gambling symptoms, subjective enjoyment of gambling and treatment readiness. Substance Use and Misuse, . doi:10.1080/10826080601094223.

Wood, R. T. A., Griffiths, M. D., \& Parke, J. (2007). Acquisition, development, and maintenance of online poker playing in a student sample. Cyber Psychology \& Behavior,. doi:10.1089/cpb.2006.9944.

Wood, R. T., \& Williams, R. J. (2009). Internet gambling: Prevalence, patterns, problems and policy options (Research report). Ontario: Ontario Problem Gambling Research Center. 